\title{
ANNOTATION
}

\section{The need for ophthalmic advice in Army Recruiting Centres}

At the beginning of the 1914-18 war a distinguished surgeon on the Director General's staff advised that there was no need for ophthalmic surgeons in the medical service of the Army, all that was necessary in the case of ocular wounds was for the general surgeons to excise the eye. It was apparently a while before it was realized that some wounded eyes could be saved, that magnetic intra-ocular foreign bodies could be extracted, traumatic cataracts removed and sockets carefully repaired and rendered fit to receive a prosthesis.

Later in addition to the base hospitals where expert ophthalmic surgery was carried out, the establishment of ophthalmic centres attached to a casualty clearing station in each Army Corps did good work by attending to soldiers with ocular ailments such as corneal ulcers, abrasions, foreign bodies, iritis and lid disorders which required treatment for a short time before returning to the line.

Refractive errors were also dealt with in these centres where an optician attended with spectacle frames and glasses. The prompt correction of these errors was a factor in reducing some of the strain on men serving in the line. The need for the ophthalmic care of hundreds of gas injuries became evident later on. In the early days of chemical warfare 2,000 eye gas casualties arrived at one C.C.S, where there was no provision for ophthalmic treatment.

Although to-day the equipment for the ophthalmic service to the Army in the field is as admirable as it could be under the circumstances of war there have been deficiencies which may be termed prophylactic in character in the admission of men whose visual acuity is not only grossly below the approved standard but in whom one or both eyes have a serious organic disorder. These errors have occurred mainly among Supplementary Reservists Category $\mathrm{C}$, a class of men holding as civilians specialist trade appointments in peace time, who were called up on general mobilization and within a week or two of the outbreak of war were sent to France to work in the docks at the base ports, on electrical installations along the lines of communications and as vehicle drivers. These men had been examined before the war on joining the Supplementary Reserve and before embarkation by "civil medical practitioners" employed by the Army. Among the first 300 returned from France as unfit for service in the Army the writer of this annotation saw cases exhibiting the following ocular disorders: aphakia with dense capsular remains and iris cyst, retinal detachment of long standing with multiple holes and old extensive choroido-retinitis, strabismus of over 70 degrees, high 
myopia with myopic degeneration of the fundus, several cases of amblyopia ex anopsia; and from units in training locally cases of mixed and see-saw nystagmus, interstitial keratitis, large coloboma of the iris after abscision for a traumatic prolapse, bilateral choroidoretinitis juxta-papillaris with extensive visual field defect, advanced pigmentary degeneration of the retina and a number of gross refractive errors which reduced the visual acuity well below the lowest standard accepted for service in the Army.

It seems that much unnecessary expense in clothing, feeding, transporting and ultimately, after some weeks of hospitalization and medical boards, discharging such men from the Army could be avoided by setting up in England a regional or county appeal centre to which doubtful cases could be sent for examination by a medical board on which an ophthalmic surgeon of approved experience should serve. Such work could be done excellently by senior ophthalmic surgeons who have retired from hospital practice and have placed their services at the disposal of the Ministry of Health.

Many of the general physical defects among the sick returned from France such as arthritis, pes cavus, paralysis after anterior poliomyelitis, cardiac disorders and other obvious defects would have been evident on a half-minute inspection of the stripped candidate.

\section{ABSTRACTS \\ MISCELLANEOUS}

(1) Weigl, R. (Lwow).-Rickettsia Rocha-Lima (Weigl) is not the cause of trachoma. (Rickettsia Rocha-Limae (Weigl) is nicht der Trachomerreger). Zentralb. f. Bakteriologie, Vol. XCLIII, March, 1939.

(1) Weigl doubts the specificity of the Weil-Felix reaction in trachoma and rejects any relationship between trachoma and typhus.

The anal infection of lice by trachomatous material gave negative results, no Rickettsia Rocha-Lima being found.

He could detect no agglutinins against Rickettsia Rocha-Lima in the sera of trachomatous patients. Nor did he do so in cases which had a relatively high titre for OX19, OXK nor even for Rickettsia Prowaczeki.

This proves that Rickettsia Rocha-Lima is not only not identical with the causal agent of trachoma but has no relationship whatever to it.

The statement made by Cuénod and Nataf that Rickettsia RochaLima is the same as the causative agent of trachoma is based on a mistake made during the experiments on lice.

A. F. MacCallan. 